\title{
SUJETO CULTURAL COLONIAL Y PRODUCCIÓN LITERARIA EN GUINEA ECUATORIAL. LECTURA SOCIOCRÍTICA DEL PRÓLOGO DE CUANDO LOS COMBES LUCHABAN (1953)' DE LEONCIO EVITA ${ }^{2}$
}

S. ONOMO-ABENA

Université de Yaoundé-I

CAMERÚM

\section{RESUMEN}

Tras un largo período de oralidad (cuentos, epopeyas), se abre otro con la publicación en 1953 de Cuando los Combes luchaban, primera novela escrita por un guineo-ecuatoriano y la única del escritor Leoncio Evita (1929-1996).

La ambición de este estudio es ilustrar cómo a través de la instancia mediadora que constituye el prólogo, se establece un discurso sobre el texto de Leoncio Evita y sobre los morenos del Golfo de Guinea. Partiendo de los planteamientos teóricos narratológicos y sociocríticos expuestos por Gérard Genette y Edmond Cros, leemos el prólogo, en primer lugar, como una de las modelizaciones específicas del

1 LeONCIO Evita ENoY, Cuando los Combes luchaban. Madrid, IDEA, CSIC, 1953. Ver prólogo en el anexo.

2 Agradecemos al profesor Victorien LAvou quien nos envió un trabajo (cf. nota 16) cuyo planteamiento nos ha sido muy útil para la elaboración de este artículo. 
campo literario y una estruetura de mediación entre el texto y el público en la literatura negro-africana; en segundo lugar, examinamos e interrogamos dicha estructura a la luz de la noción de sujeto cultural colonial tal como lo define el Profesor Edmond Cros en El sujeto cultural: sociocrítica y psicoanálisis.

La deconstrucción del prólogo de Cuando los Combes luchaban descubre las articulaciones y los fundamentos del discurso colonial. Del estudio realizado se observa que tanto el discurso de Carlos González Echegaray en el prólogo como posteriormente la novela de Leoncio Evita, los dos están influenciados por el pensamiento monolítico «oficial» e «imperial" sobre la colonización. El prólogo de Carlos González Echegaray, entonces Delegado del Instituto de Estudios Africanos (I.D.E.A), o sea máximo representante del aparato ideológico colonial de la España franquista, refleja las relaciones que han existido entre el Blanco y el Negro y aclara las representaciones que se hacian unos de otros.

Cuando los Combes luchaban es la primera novela escrita por un guineano y la única del escritor Leoncio Evita Enoy (1929-1996). Es el texto fundador de la narrativa guineo-ecuatoriana en lengua española. Esta novela no sólo aporta un soplo nuevo e innovador en la incipiente literatura guineana sino también desmonta muchos de los tópicos que presentan los colonizadores y los exploradores europeos bajo el prisma de la situación colonial. Estas palabras atraen la atención sobre el lugar que ocupa la novela de Leoncio Evita dentro de la historia literaria guineana y, por ende, el prólogo de Carlos González Echegaray, un prólogo cuya importancia se nota en cuanto que es el que presenta la primera novela de la narrativa guineana. Proceder a la deconstrucción de dicho prólogo nos conducirá a determinar unos elementos constitutivos del sujeto cultural ecuato-guineano.

La obra de Leoncio Evita, una narración generalmente en tercera persona, consta de un centenar de páginas (101 páginas). Los once capítulos que la componen siguen un orden secuencial y describen no sólo las costumbres y los ritos de la etnia Combe, la del autor, como ha querido limitarla Carlos González Echegaray desde el principio, sino también las peripecias que atraviesan los múltiples personajes de la obra para acabar con la secta bwiti ${ }^{3}$ que siembra terror y hambre en los pueblos de Ndyebengo y Bolondo.

El prólogo de la primera edición de 1953 está a cargo de Carlos González a petición del autor. Carlos González, en aquel entonces funcionario de Archi-

${ }^{3}$ Bwiti: se trata de una sociedad secreta mixta, una secta de hombres-leopardos que nació en Gabón en la etnia Fang. Se propagó en el sur de Guinea Ecuatorial, en la zona de Río Muni. El «iboga» planta alucinógena, juega un papel importante en el culto bwiti. La ingestión de esta planta permite «pasar al otro mundo». Se puede asimilar el bwiti a la religión del «iboga». 
vos y Bibliotecas y delegado del Instituto de Estudios Africanos (I.D.E.A) en la Guinea Española, es una de las figuras de primera fila en la promoción de las letras guineo-ecuatorianas. Es uno de los máximos conocedores, dentro del mundo africanista intelectual español, de la producción cultural de Guinea Ecuatorial.

En este artículo nos proponemos estudiar el prólogo, que es a la vez un discurso sobre el texto de Leoncio Evita y un discurso sobre «sus morenos» del Golfo de Guinea. Nuestro propósito es doble. Se tratará en primer lugar de leer el prólogo como una de las modelizaciones específicas del campo literario y, tratándose de la literatura negro-africana en particular, como una estructura de mediación obligatoria entre el texto y la sociedad o el público. En segundo lugar, intentaremos examinar e interrogar dicha estructura a la luz de la noción de sujeto cultural colonial tal como lo define el Profesor Edmond Cros en su libro fundamental El sujeto cultural: sociocrítica y psicoanálisis ${ }^{4}$ del que se nutre nuestra reflexión.

El prólogo es esta «frange du texte imprimé qui, en réalité, commande toute la lecture» ${ }^{5}$. Como los demás elementos del paratexto, el prólogo es pues una zona no solamente de transición sino principalmente de «transacciones», «lieu privilégié d'une pragmatique et d'une stratégie, d'une action sur le public au service, bien ou mal accompli, d'un meilleur accueil du texte et d'une lecture pertinente...» ${ }^{6}$

Los diccionarios sólo definen el prólogo como un escrito antepuesto al cuerpo de una obra o a un libro de cualquier clase, escrito cuya función es la de presentar o de exponer lo que se va a desarrollar después. Sin embargo, estas definiciones de los diccionarios no dan cuenta de todos los valores simbólicos e ideológicos que encierra el prólogo?.

Gérard Genette, en su ya citado libro Seuils, distingue dos tipos de prólogo/ prefacio ${ }^{8}$ y según se trate de un prefacio «auctorial» (es decir, el que escribe el propio autor) o de un prefacio «allographe» (es decir, un prefacio escrito por otra persona), el prefacio no tiene la misma significación. El prefacio de Cuando los Combes luchaban pertenece a la categoría de "préface allographe». Generalmente se convoca la instancia del prólogo/ prefacio, sea por-

${ }^{4}$ Edmond Cros, El sujeto cultural: sociocrítica y psicoanálisis. Versión española de Rosa Parra Valiente, Buenos Aires, Corregidor, 1997.

5 PhilipPe Lejeune, Le Pacte autobiographique, Paris, Seuil, 1975, p. 45.

- Gérard Genette, Seuils, Paris, Seuil, 1987, p. 8

7 Henri Mitterand, Le discours du roman, Paris, P.U.F., Écriture, 1980.

" Para Gérard GénetTe, existe una parasinonimia entre los términos siguientes: "préface», «prologue», «avant-dire», «proème», «introduction», «présentation,» etc. 
que va a contracorriente de la doxa, de las ideas generalmente compartidas y admitidas sobre cualquier asunto, sea porque inaugura una nueva escritura.

En cuanto al concepto de «sujeto cultural» como elemento de mediación entre lenguaje y discurso, el Profesor Edmond Cros, que se apoya en los trabajos realizados por P. Bourdieu, L. Althusser, E. Benveniste, J. Lacan y J.D. Nasio, lo define de este modo: «Cuando hablo de sujeto cultural, designo pues al mismo tiempo:

- Una instancia de discurso ocupado por Yo;

- La emergencia y el funcionamiento de una subjetividad;

- Un sujeto colectivo;

— Un proceso de sumisión ideological» ${ }^{9}$.

A continuación añade: «La cultura no es una idea abstracta. Como lo recordaba Louis Althusser al referirse a la ideología, la cultura no posee existencia ideal, sólo existe a través de sus manifestaciones concretas, es decir:

1. El lenguaje y las diversas prácticas discursivas;

2. Un conjunto de instituciones y prácticas sociales;

3. Su particular manera de reproducirse en los sujetos, conservando, sin embargo, idénticas formas en cada cultura» ${ }^{10}$.

Partiendo de estas premisas, podemos decir que el prólogo de Cuando los Combes luchaban escrito por Carlos González Echegaray da una idea, parcial pero de por sí muy importante, de las representaciones que los colonizadores mediante la literatura hacían con respecto a los guineanos. Dentro de las dimensiones de este trabajo, sería ilusorio pretender dar cuenta del «sujeto cultural colonial» en su totalidad, en toda su complejidad. Se trata para nosotros, a partir de la definición del prólogo que Edmond Cros considera como un espacio proyectado de identificación ${ }^{11}$ y lugar privilegiado donde se manifiesta el imaginario colectivo, de leer el prólogo de Carlos González como un lugar de expresión de las preocupaciones ideológicas del africanismo literario español en particular y del africanismo español en general.

Cuando Carlos González recibe el texto de Leoncio Evita, no lo toma en serio. Afirma: «no le di (a Leoncio Evita) palabra de escribírselo hasta que no

${ }^{9}$ EDMOND CROS, op. cit., p. 9.

11" Idem, p. 10.

$"$ EDMONd CROS, D'un sujet à l'autre: sociocritique et psychanalyse, Montpellier, CERS, 1995, p. 9. 
me convenciera de que se trataba de algo distinto de los relatos inconexos y absurdos que algunos morenos seudo-intelectuales escriben...» Según él, los «morenos» son incapaces de producir un discurso coherente. A continuación dice: "Pero mi sorpresa fue en aumento a medida que iba leyendo, al encontrarme con una obrita ${ }^{-12}$ francamente aceptable, y que bien pudiera haber sido escrita por cualquier escritor novel nacido en nuestra Patria». Estas palabras resumen la visión del mundo de Carlos González quien, en cuanto subjetividad transindividual, cultural y social, traduce la ideología del colonizador, el que considera que la producción literaria es propiedad de los europeos. Al emitir un punto de vista positivo para la publicación de la obra, permite al mismo tiempo el reconocimiento de Leoncio Evita por el círculo de los defensores de la literatura colonial que piensan que la literatura es una actividad reservada sólo a los blancos. En el prólogo a la 2. ${ }^{a}$ edición (Centro Cultural Hispano-Guineano, Malabo, 1996) el propio Carlos González subraya esta paradoja: «Es curioso comprobar cómo una iniciativa que resultaba políticamente rentable para la administración colonial española, al presentar el resultado positivo de una estructura educacional (...), al mismo tiempo paradójicamente venía a desterrar la idea de un africano atrasado e imposible de integrar plenamente en la cultura europea» (p. 14). Cabe decir que la obra es publicada por el Instituto de Estudios Africanos (creado en 1945), un organismo del Consejo Superior de Investigaciones Científicas, aparato de propaganda del franquismo. El Instituto de Estudios Africanos se encarga, además de la revista Archivos, de la publicación de la mayor parte de la literatura española escrita sobre África después del final de la Segunda Guerra Mundial.

Este discurso de Carlos González no es nuevo. Ya lo encontramos en muchos escritos de la literatura colonial. Nos recuerda lo que ya dijo José Mas Laglera, otra figura de la literatura colonial española sobre Guinea, cuando escribe acerca de la novela Batouala. Véritable roman nègre (1921) de René Maran, novela que acababa de ser traducida al español: «La novela —escribe José Mas- no sólo era de negros, sino que estaba escrita por un individuo perteneciente a esta raza. El caso me pareció insólito. Yo no podía concebir que un negro del Congo tuviese aptitudes de escritor. Sabía que, educándoles en Europa, llegaban a ser buenos bailarines, y que algunos hasta habían logrado tocar la trompeta y el violín con verdadero arte; pero de esto a describir paisajes y estados de almas, había mucha distancia» ${ }^{13}$. Como José Mas unos años antes,

12 El subrayado es nuestro.

13 José mas Lagliera, «Prólogo» a Batuala. Verdadera novela de negros, Madrid, V.H., Sanz Calleja Editores e Impresores, 1992. 
González Echegaray tampoco esconde su sorpresa al darse cuenta, tras leer la novela de Leoncio Evita, de que un negro pudiera escribir un texto «acceptable». Sus dudas se desvanecen. José Mas, como para rematar, agrega: «Renato Maran no tiene de negro más que el color de la piel». Lo mismo defiende Carlos González al apuntar que «la novela [de L. Evita] está pensada y sentida en blanco». Se desprende de estas palabras de Carlos González y de José Mas que el mito del no-racismo ${ }^{14}$ del español es falso, la realidad es diferente. Muchos ejemplos lo atestiguan. Basta citar uno. En 1887, el Padre Pinosa, un clérigo, no escondía sus concepciones racistas. Refiriéndose a los Bubis, que son los autóctonos de la Isla de Bioko (antigua Fernando Poo), afirmaba: «Los bubis. Esta palabra significa hombre, pero de muy inferior condición a los demás, sobre todo a los blancos, motivo por el cual pueden ejercer éstos un dominio absoluto sobre los mismos» ${ }^{15}$. Cabe decir que el concepto de Hispanidad, que fue formulado por primera vez por Ramiro de Maeztu en 1934, preconiza la unión de todos los pueblos conquistados por España bajo una misma entidad común. La pretendida vocación misionera de España no era únicamente «civilizadora», el colonialismo español era como todos los colonialismos europeos y participaba en los componentes universales de la mentalidad colonial: explotación, dominación, etc.

A la lectura del prólogo de González Echegaray, surge en el telón de fondo una visión discriminatoria y despectiva de todo discurso colonial. Como ya lo decíamos más arriba, puede parecer reductor el limitar nuestro examen del sujeto cultural colonial sólo al estudio del discurso/prefacio de González Echegaray. Pero al mirar más de cerca, vemos que este discurso sigue vigente en la actualidad. En efecto, se puede observar que a pesar de la distancia que separa las novelas Cuando los Combes luchaban de Leoncio Evita - 1953- y Ekomo de María Nsue Anguie - 1985- el prólogo de C. González para la primera obra y el de Vicente Granados para la segunda expresan la visión dirigida al escritor guineoecuatoriano. Los dos prologuistas reconocen el valor y los esfuerzos de los dos escritores. Los consideran como plumas prometedoras. Estas mismas estructuraciones observables entre los dos prólogos son reveladoras de una semejante concepción del escritor guineano. Esto quiere decir que desde los orígenes de la literatura producida en Guinea hasta hoy, la visión que tienen las instancias que encabezan la Institución literaria española no ha va-

14 SÁEZ y muchos otros ideólogos franquistas defendían que «nunca tuvieron los españoles el complejo de superioridad que pareció distinguir a la raza blanca en el colonialismo». (Sáez, 1971: 28 y 127 )

15 Cristóbal Fernández (1962: 224), citado por Gustau Nerín, Guinea Ecuatorial, Historia en blanco y negro, Barcelona, Ed. Península, 1998, p. 43. 
riado a propósito de la capacidad lingüística, mental y cultural del guineo-ecuatoriano. Lo que puede explicar sin duda la dificultad que tiene la literatura guineana para imponerse en los círculos intelectuales en España. Carlos González y Vicente Granados parecen detener las «llaves» que abren el mercado de los bienes simbólicos a la literatura guineana como parecen detener las «llaves» de las instancias que confieren la legitimidad a dicha literatura. Sus prefacios son pues fundamentales para determinar los diferentes aspectos del sujeto cultural colonial balizando el discurso ideológico de la instancia "préfacielle»; un discurso que se construye en torno a las parejas antitéticas colonizador/colonizado; superioridad/ inferioridad; capacidad/ incapacidad; dominante/ dominado. Este discurso es regulado río arriba por la ideología de la raza superior del colonizador que establece la sinonimia «indígena = no-evolucionado». Siempre en el prólogo a la 2.a edición, Carlos González reconoce que «naturalmente, tanto a lo largo de la novela, como en mi prólogo -mea culpa-, se advierte claramente la influencia del pensamiento oficial sobre la colonización» (p. 14).

El prólogo vuelve a ser así un espacio de negociación o si se prefiere de tensión entre el prologuista y la sociedad destinataria que va a leer la obra. Frente a los textos antiguos ya consagrados, el nuevo texto debe «forjarse» un camino en un mundo que Bourdieu denomina «marché des biens symboliques», un mercado marcado por unos «habitos» de escritura y de lectura de los clásicos. Carlos González tiene pues que justificar su apoyo y dar su aval para la publicación de la obra de Leoncio Evita, una obra que despierta curiosidad tanto a nivel temático (sus fuentes etnológicas) como a nivel del estilo y de la lengua. Esta actitud de González Echegaray, a pesar de la ideología colonialista que defiende, es la prueba de su africanismo y de su amor para con Guinea.

A lo largo del texto se nota la expresión de un yo - Carlos Gonzálezque, a través de la plasmación de una visión del mundo predeterminada por los clichés y los estereotipos, deja emerger el funcionamiento de su subjetividad que en el fondo representa un sujeto colectivo dentro de un proceso de sumisión ideológica. O sea, todos estos componentes que permiten hablar de «sujeto cultural» tal como lo designa el Profesor Edmond Cros.

De lo que precede, se destaca que el discurso del prólogo transcribe a la vez preocupaciones estilísticas, temáticas e ideológicas. No es sólo un metadiscurso (discurso sobre el texto/novela) sino también un discurso ideológico. Para ver aceptado su manuscrito, Leoncio Evita necesita, como acabamos de decir, el aval de una figura de primer orden dentro del «establishment» cultural de la España franquista. El prefacio vuelve a ser desde este punto un requisito previo o si se prefiere un verdadero rito de pasaje. Esta situación no es privativa de los escritores de Guinea Ecuatorial tal como lo hemos mostrado en líneas anteriores, se verifica también en los prólogos de la mayor parte de la 
producción literaria de los escritores africanos francófonos. A este respecto, Locha Mateso apunta: «L'objet de la préface est de préparer le public français à son rôle de récepteur des œuvres des écrivains noirs (...) Il est donc à la fois une leçon d'écriture par la somme d'indications, de remarques, voire de remontrances adressées par l'écrivain de métier à son pupille négro-africain et, d'autre part, un plaidoyer en faveur de ce dernier éludant les questions véritablement littéraires mais mettant l'accent sur les qualités intellectuelles et morales de l'écrivain et la conformité de son œuvre à la doctrine du colonialisme littéraire précédemment définie» ${ }^{16}$.

Tales observaciones de Locha Mateso son comprobables igualmente en el prólogo de la obra de Leoncio Evita en particular y en toda la producción literaria guineo-ecuatoriana en el área cultural hispanófona. A la lectura del texto de Locha Mateso, Victorien Lavou observa una doble articulación que se pone en evidencia en éste, y, relacionándolo con su análisis del prólogo de Ekomo, deduce: «Le prologue est (nous semble-t-il) moins un discours d'intronisation, c'est-à-dire faire accepter un produit finalement exotique, le roman de NSUE en l'occurrence, à un public peu familiarisé avec la littérature équato-guinéenne en le présentant comme quelque chose digne d'intérêt (littéraire), qu'un discours d'autorité, un discours normatif» ${ }^{17}$.

Hay que observar que el prefacio de González Echegaray, enunciado desde una postura condescendiente («la obra fue leída por mí»), dice cómo se debe escribir y qué es lo que se debe hacer: «En cuanto al estilo, he corregido algunas construcciones excesivamente extrañas a nuestra sintaxis...» Reconoce los esfuerzos realizados por el «joven novel» L. Evita cuando éste pone «las notas que acompañan a la obra [y que] son interesantísimas como fuentes etnológicas». Por ello el texto tiene cierto mérito como se destaca en el penúltimo párrafo.

Llama poderosamente la atención la utilización de «nuestro» (4 veces): «nuestra Patria», «nuestra Guinea», «nuestra sintaxis», «nuestros negros», que evidencia la idea de apropiación y de pertenencia. Marca también el pasaje de la postura de enunciación del «yo» prologuista Carlos González a un «nosotros» que se refiere aquí a todos los colonos entre los que se incluye el «yo» prologuista. A partir de la expresión «nuestros negros» se despeja una relación blanco vs. negro caracterizada por la ambigüedad paternalismo/humanismo vs.

${ }^{16}$ LoCha Mateso, La littérature africaine et sa critique, Paris, ACCT et Editions Karthala, 1986, pp. 84-85. Citado por VICTORIEN LAVOU, «sujet culturel colonial et production littéraire: une approche sociocritique du prologue de Ekomo de MARfa NsUE ANGÜE», VI Congrès International de sociocritique, Granada, 1999, p. 6 (en prensa).

i) Victorien Lavou, art. cit, p. 6. 
coloniaje/explotación. En el discurso del prologuista, se manifiesta el mito de la vocación humanista y civilizadora de España iniciada durante la Época Medieval, la de Isabel la Católica y continuada en la Época Renacentista, un mito que recupera el discurso ideológico franquista el Nacional-Catolicismo: «... la mayor y mejor parte del pueblo combe ha entrado en la religión católica gracias al constante esfuerzo de los citados misioneros Hijos del Corazón de María, y particularmente del hoy Vicario Apostólico de Fernando Poo, excelentísismo y reverendísimo padre Leoncio Fernández, cuyo personal apostolado entre estas tríbus de la playa, le hace merecedor al sobre nombre de apóstol de los combes».

Así Cuando los Combes luchaban es a la vez una novela de ruptura y una novela pretexto. Es una novela de ruptura porque ve la aparición de la primera personalidad literaria guineana. En efecto, huelga decir que durante el periodo colonial, la literatura guineana está a cargo de los exploradores, geógrafos, misioneros y otros aventureros, todos defensores y promotores de los intereses de la colonia. La revista La Guinea Española, bimensual (1903-1968), publicada por los misioneros del Inmaculado Corazón de María (los Claretianos) abre sus páginas sólo a personalidades coloniales. Los indígenas accederán a ella en 1947 cuando, por fin, se abre para ellos una sección Historias y cuentos así definida: «Esta nueva sección que hoy comenzamos, un exponente del pensamiento de nuestros indígenas recogido tradicionalmente en cuentos, historias, narraciones, refranes y cantos, contribuyendo de esta suerte a perpetuarlos y a divulgarlos...». En aquella ocasión, los textos que fueron presentados eran meras traducciones de las epopeyas y cantares orales recopilados por los alumnos de los seminarios y los pocos maestros autóctonos. Esta etapa es la de las primeras manifestaciones, de los primeros balbuceos. En 1953 cuando Leoncio Evita publica Cuando los Combes luchaban, inaugura la literatura escrita guineana rompiendo así con la etapa «impersonal» anterior.

También es una novela pretexto porque, como nos explicó el propio autor en 1994 cuando nos hizo el honor de visitar nuesta Universidad, su proyecto de escritura era un desafío que tenía que aceptar, el de mostrar al colonizador que el Negro puede desarrollar una reflexión coherente. De este modo va en contra de las ideas recibidas y del discurso colonial que menosprecia la capacidad intelectual de los indígenas. La obra de Leoncio Evita se convierte en el relato de la insumisión al orden establecido. $Y$ aunque parezca parodójico, es la mentalidad colonial la que estimula al autor a escribir su novela. Pero su discurso se produce desde una posición de enunciación subalterna. Lo que impide toda crítica frente a la acción colonial. De hecho, a lo largo de la novela, la instancia ideológica no cesa de manipular la instancia narradora, «no deja de ser curioso - observa C. González- el hecho de que la novela 
está pensada y sentida en blanco, y sólo cuando la acción se desarrolla entre indígenas, solamente en parte, y como espectador, el escritor se siente de su raza». ¿Podría ser de otra forma en 1953? Cuando sabemos que la obra debía obedecer a los cánones y a los intereses de la superestructura colonial. El Régimen franquista en el poder desde 1939 controla la cultura. Eso puede explicar la actitud de C. González Echegaray quien declara que si la obra merece ser publicada, aparte de ser una «prueba de las buenas relaciones que siempre han existido entre los españoles y las misiones protestantes extranjeras en la Guinea» es porque la obrita «atestigua la sincera opinión (...), que a un indígena evolucionado, le merecen el carácter y la colonización de los españoles con sus pequeños defectos temperamentales - violencia, irreflexión, orgullo- y sus virtudes fundamentales - generosidad, fe, sencillez, entusiasmoy, especialmente, su denotado valor, que ha sido siempre el imán de la admiración entusiasta de los indígenas».

En efecto, la «admiración entusiasta de los indígenas» se manifiesta en la obra a través de las representaciones positivas que el narrador hace de los personajes blancos que «han sido enviados por Rambé (Dios) para que nos traigan civilización» (p. 14). En el relato todos los personajes blancos se nos muestran retratados positivamente. Un ejemplo para ilustrarlo: «Mama Stephen, como la miss era conocida por las negritas, era algo gruesa, pero bien proporcionada. Rubia, bonita como una española» (p. 19). Al contrario, los negros siempre «ninguneados» son unos «insanos» (p. 20) y unos salvajes ( Roku era salvaje», p. 13), poco receptivos a la «educación» (p. 19) del blanco: «Esto de educar negras me parece más difícil cada día", dice Miss Leona -y su marido el pastor John Stephen añade: «Los potros más salvajes resultan mejor domados» (p. 21). La obra es pues un pretexto para presentar la acción civilizadora de los blancos. La destrucción de la secta bwiti tras la larga y peligrosa expedición dirigida por dos aventureros españoles Martín y Carlos Garrido, con sus escopetas, bajo la protección (divina) del pastor americano John Stephen, es la metáfora del aniquilamiento de la tradición y el símbolo de la victoria de la cultura occidental, aunque de vez en cuando araña al colonizador: «Lo cierto es que, aunque el salvaje no sabía atribuir a los blancos la precisa calificación, éstos, a pesar de su interés por traficar, habían traído la más sana intención de civilizar» (p. 14).

El hecho es que si unos - empezando por el propio autor- han querido ver en Cuando los Combes luchaban una mera crítica y una condena de las costumbres del pueblo Combe, olvidando que eso era para complacer al blanco, nosotros observamos que en la obra de Leoncio Evita transpira en filigrana la rebeldía aunque tímida. El mismo autor desvelaba a Mbare Ngom: "Sentí gran satisfacción por abrir aquella pequeña brecha en el dique del mo- 
nopolio de discriminación intelectual reinante» ${ }^{18}$. Se trata en efecto de una rebeldía contra las ideas según las cuales los negros poseen unas inteligencias de niños dentro de cuerpos de adultos ${ }^{19}$. Cuando los Combes luchaban se publica en medio de una literatura dominada por los blancos. Los primeros «autores indígenas», según Mbare Ngom «eran, en definitiva meras correas de transmisión de la producción cultural de su propio grupo étnico. Los textos que producían no se podían considerar trabajos personales de creación estética, sino que se trataba más bien de una operación de colectación, de transcripción y de traducción al castellano de la producción literaria tradicional del grupo étnico al que pertenecían» ${ }^{20}$. Por primera vez el Guineano, considerado hasta entonces como objeto, un tópico, «celui dont on parle», asume su discurso. Obra de vanguardia, Cuando los Combes luchaban aparece como un relato programático de la narrativa guineoecuatoriana posterior. Esta obrita marca el comienzo del largo camino que conduce hacia la afirmación de la identidad cultural y lingüística híbrida de Guinea Ecuatorial. Pone las bases de los elementos de esta construcción identitaria, unos elementos que se manifiestan a nivel de la sintaxis -que Carlos González critica- y a nivel del léxico con el uso de localismos que favorecen la fijación del relato en el entorno cultural y simbólico africano.

En lugar de ver en estas nuevas aportaciones lexicales y sintácticas del español guineano un enriquecimiento del español de la metrópoli —cegado como está por la ideología de la defensa de la pureza de la lengua (raza) - el prologuista González Echegaray ve únicamente que el nivel de la lengua es el de un «indígena evolucionado». Creyendo subsanar al corregir «algunas construcciones excesivamente extrañas a nuestra sintaxis», ha empobrecido lo que puede ser considerado dentro de la Hispanofonía como la aportación de Guinea Ecuatorial a la lengua española. Influenciado por el pensamiento monolítico «oficial» e «imperial» sobre la colonización, no ha sabido valorar -como muchos otros después - las aportaciones linguísticas de Leoncio Evita ya que éste hace que el español se enriquezca. Es esta sintaxis la que comunica el relato de este medio ambiente africano. Cuarenta y tres años después (19531996), con motivo del segundo prólogo a la obra, Carlos González revisa su opinión anterior y hace su mea culpa: «A propósito del estilo - escribe- he de confesar que realicé con gusto la corrección de aquél, aunque sospecho ahora que quizá he contribuido sin querer a dificultar trabajos posteriores, como el

18 Mbaré Ngom, Diálogos con Guinea, Madrid, Ed. Labrys, 1996, p. 31.

19 Bravo Carbonell, Territorios españoles del golfo de Guinea, Madrid, S.E., 1929.

20 Mbaré Ngom, NDongo Bidyogo. Donato, «Introducción» a Literatura de Guinea Ecuatorial (Antologia). Madrid, Casa de África, 2000, p. 17. 
que últimamente han llevado a cabo con éxito los profesores Antonio Quilis y Celia Casado-Fresnillo en su libro El español hablado en Guinea Ecuatorial; para ellos hubiera sido una fuente intacta de giros estilísticos propios de un castellano dialéctico hablado por un joven ndowé, con un nivel educativo de grado medio» (p. 16).

Es fácil imaginar por qué la obra de Leoncio Evita quedó olvidada totalmente por la crítica española - como ocurre con los demás autores guineanos- por razones evidentes: el desinterés y el desprecio de todo lo procedente de Guinea y las dificultades de la crítica conservadora española a abrirse a lo heterogéneo, es decir, a aceptar las formas «impuras» que son el fruto de un hibridismo cultural. Leoncio Evita demuestra en su obra su lealtad a su cultura y a su tradición frente a la educación española que ha recibido. La escritura de Leoncio Evita, como la de Donato Ndongo, Juan Balboa, María Nsue Angüe, Ciriaco Bokesa y de los demás, es en definitiva el resultado del encuentro de dos prácticas discursivas diferentes pero complementarias: el texto oral africano y el texto escrito europeo. Los cuentos, los proverbios que confieren un color local a los textos guineanos constituyen tantas estrategias de integración de las lenguas locales en una escritura bi- o plurilinguie: español, fang, bubi, pichinglis, ndowe, etc. Lo que deja entrever la emergencia de una literatura nacional afrohispánica bantú cuyas especificidades podrán ser reconocidas por toda la comunidad hispánica. Dicho reconocimiento pasa también por la creación, ya, de una Academia Guineoecuatoriana de la lengua, filial de la Española, a la imagen de lo que ocurre en el resto de los países hispanoamericanos, una Institución que los intelectuales y escritores guineanos llaman a gritos desde hace un lustro.

A modo de conclusión, podemos decir que la instancia mediadora, el sujeto cultural, cuya operatividad en el análisis de textos ya ha sido probrada, nos ha llevado a explicitar las articulaciones y los fundamentos del discurso colonial a partir de la deconstrucción del prólogo de Cuando los Combes luchaban. Del estudio realizado, se despejan unas conclusiones acerca de las representaciones del sujeto cultural colonial en Guinea Ecuatorial.

Por una parte:

- En cada momento del encuentro entre el blanco y el negro, el primero ha querido hacer brillar su cosmovisión, la visión del hombre superior, la visión del dominador no sólo en el plano religioso sino también en el plano cultural;

- El prólogo de Carlos González es un discurso etnocentrista marcado por el menosprecio del Otro al que se niega la religión, la historia, la escritura y la cultura. 
Por otra parte, es interesante observar que se publica la obra de Leoncio Evita cuando España lucha para conservar su colonia del Golfo de Guinea, poniendo trabas a su independencia política. De ahí se puede hablar de un proceso de descolonización mental que surge después de la apertura de las páginas del órgano cultural La Guinea Española a las «plumas indígenas».

Finalmente diremos que las representaciones del sujeto cultural colonial que formula el prólogo de Carlos González Echegaray siguen siendo actuales en las producciones culturales de Guinea Ecuatorial en particular, y en las producciones culturales africanas y europeas en general; unas producciones culturales que transmiten corrientes de pensamientos marcadas por la diferencia de unos con respecto a otros, o sea, unos «productos discursivos de la noción de lo desemejante, de lo diferente».

\section{Bibliografía}

CROS, Edmond, D'un sujet à l'autre: sociocritique et psychanalyse, Montpellier, CERS, 1995.

Cros, Edmond, El sujeto cultural: sociocrítica y psicoanálisis, Buenos Aires, Ediciones Corregidor, 1997.

CROS, Edmond, Genèse socio-idéologique des formes, Montpellier, CERS, 1998.

Evita Enoy, Leoncio, Cuando los Combes luchaban, Madrid, IDEA, 1953. Reeditada por el Centro Cultural Hispano-Guineano en 1996, con estudios introductorios de Carlos González Echegaray, Augusto Iyanga Pendi y Donato NdongoBidyogo.

Genette, Gérard, Seuils, Paris, Ed. du Seuil, 1987.

Liniger-Goumaz, Max, La Guinée Equatoriale. Un pays méconnu, Paris, Ed. L'Harmattan, 1979.

Mbaré NGom, Faye, Diálogos con Guinea, Madrid, Ed. Labrys, 1996.

NDONGo-Bidyogo, Donato y MBARÉ NGOM, Literatura de Guinea Ecuatorial (Antologia), Madrid, Casa de África, SIAL Ediciones, 2000.

Nerín, Gustau, Guinea Ecuatorial, historia en blanco y negro, Barcelona, Ediciones Península, 1998.

NSUE ANGÜE, María, Ekomo, Madrid, Universidad Nacional de Educación a Distancia, 1985.

OCHA A MVE, Constantino, Semblanzas de la Hispanidad, Madrid, Ediciones Guinea, Anzos, 1985.

SAEZ dE Govantes, Luis, El africanismo español, Madrid, IDEA, CSIC, 1971. 


\section{ANEXo}

Siempre es cosa difícil prologar una novela, si se quiere hacer con un criterio imparcial y exclusivamente literario, porque de no hacerlo así suele caerse en la alabanza, que muchas veces puede ser inmerecida. Por eso, cuando Leoncio Evita me dió a leer su novela y me pidió que le hiciera un prólogo, no le di palabra de escribirselo hasta que no me convenciera de que se trataba de algo distinto de los relatos inconexos y absurdos que algunos «morenos» seudointelectuales escriben, más para su satisfacción personal que con esperanza de verlos publicados.

Pero mi sorpresa fue en aumento a medida que iba leyendo, al encontrarme con una obrita francamente aceptable, y que bien pudiera haber sido escrita por cualquier escritor novel nacido en nuestra Patria.

Tiene Cuando los combes luchaban, aparte del valor puramente anecdótico de ser la primera novela escrita por un moreno de la Guinea Española, el de constituir un fiel y minucioso testimonio de costumbres y ritos hoy desaparecidos y que el joven Evita ha aprendido de sus mayores, que formahan parte de una de las más prestigiosas familias de la tribu «combe» $O$ "ndowé». Desde este punto de vista, las notas que acompañan a la obra son interesantísimas como fuentes etnológicas.

En cuanto al estilo, he corregido algunas construcciones excesivamente extrañas a nuestra sintaxis y algunos errores de propiedad en la aplicación de los vocablos castellanos, pero he dejado a la obra en su estilo propio, que a las veces puede parecer en la forma, duro, y en el fondo, ingenuo, pero que es una muestra estilizada del castellano medio, hablado por nuestros negros.

No deja de ser curioso el hecho de que la novela está pensada y sentida "en blanco", y sólo cuando la acción se desarrolla entre indígenas, solamente en parte, y como un espectador, el escritor se siente de su raza.

Pudiera extrañar al lector que desarrollándose la acción de la novela en una colonia española, sea uno de los protagonistas un pastor protestante extranjero. Todo tiene su explicación: El clan de los combes de Río Benito, al cual pertenecian los antepasados del joven autor-católico ferviente-fue evangelizado por los misioneros protestantes a fines del pasado siglo. Por aquella época ya existían también en lo que hoy es nuestra Guinea, misiones católicas pero unas estaban más al norte del teatro de esta novela (misioneros franceses, ya que entonces esa zona pertenecía a Francia) y los otros más al sur, que eran los misioneros españoles claretianos, en las islas de Corisco y los Elobeyes y en Cabo San Juan y Estuario del Muni. Posteriormente la mayor y mejor parte del pueblo combe ha entrado en la religión católica gracias al constante esfuerzo de los citados misioneros Hijos del Corazón de María, y 
particularmente del hoy Vicario Apostólico de Fernando Poo, excelentísimo y reverendísimo padre Leoncio Fernández, cuyo personal apostolado entre esas tribus de la playa, le hace merecedor al sobrenombre de "apóstol de los comhes», de la misma manera que se ha llamado «apóstol de los bubis» a aquel otro claretiano insigne, el padre Aymemí, que tan poderoso impulso dió a la evangelización de Fernando Poo.

Valga también esta novelita como una prueba de las buenas relaciones que siempre han existido entre los españoles y las misiones protestantes extranjeras en la Guinea, relaciones desarrolladas siempre en un ambiente de tolerancia, en contra de las falaces insidias que algunas sectas han querido arrojar sobre la conducta de España en la política religiosa.

$Y$, al mismo tiempo, atestigua la sincera opinión (la obra fue leída por mi recién escrita y sin censuras), que a un indígena evolucionado, le merecen el carácter y la colonización de los españoles con sus pequeños defectos temperamentales —violencia, irreflexión, orgullo-y sus virtudes fundamentales -generosidad, fe, sencillez, entusiasmo-, y, especialemente, su denodado valor, que ha sido siempre el imán de la admiración entusiasta de los indigenas.

(Carlos GONZÁLEZ ECHEGARAY, «Prólogo» a Cuando los Combes luchaban, ed. cit.) 